Portland State University

PDXScholar

9-1997

\title{
The Effectiveness of Planned Transitions Therapy in the Treatment of Three Children with Developmental Verbal Dyspraxia
}

Emily M. Campbell

Portland State University

Follow this and additional works at: https://pdxscholar.library.pdx.edu/open_access_etds

Part of the Communication Sciences and Disorders Commons

Let us know how access to this document benefits you.

Recommended Citation

Campbell, Emily M., "The Effectiveness of Planned Transitions Therapy in the Treatment of Three Children with Developmental Verbal Dyspraxia" (1997). Dissertations and Theses. Paper 5747.

https://doi.org/10.15760/etd.7618

This Thesis is brought to you for free and open access. It has been accepted for inclusion in Dissertations and Theses by an authorized administrator of PDXScholar. Please contact us if we can make this document more accessible: pdxscholar@pdx.edu. 


\section{THESIS APPROVAL}

The abstract and thesis of Emily M. Campbell for the Master of Science in Speech

Communication: Speech and Hearing Science were presented June 2, 1997, and accepted by the thesis committee and the department.

COMMITTEE APPROVALS:

Mary Gordon-Brannan, Chair

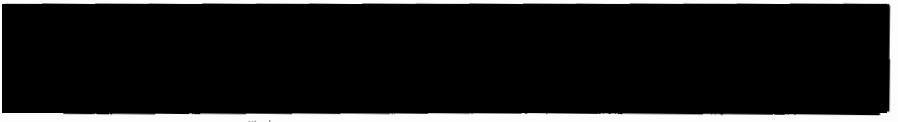

Charlene Clark

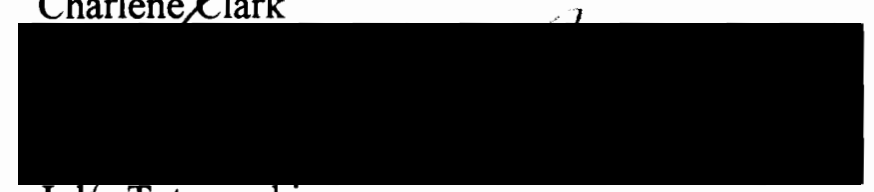

John Tetnowski

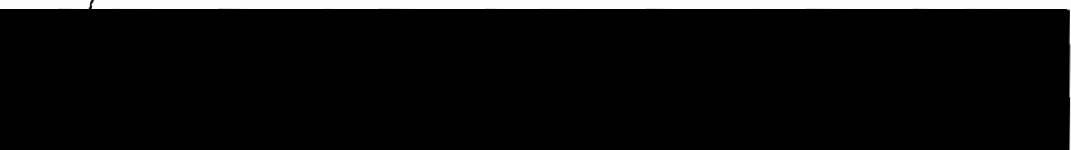

Ueanie Parker Edwards

Representative of the Office of Graduate Studies

DEPARTMENT APPROVAL:

Stephen A.'Kosokott, Chair

Department of Speech Communication

ACCEPTED FOR PORTLAND STATE UNIVERSITY BY THE LIBRARY
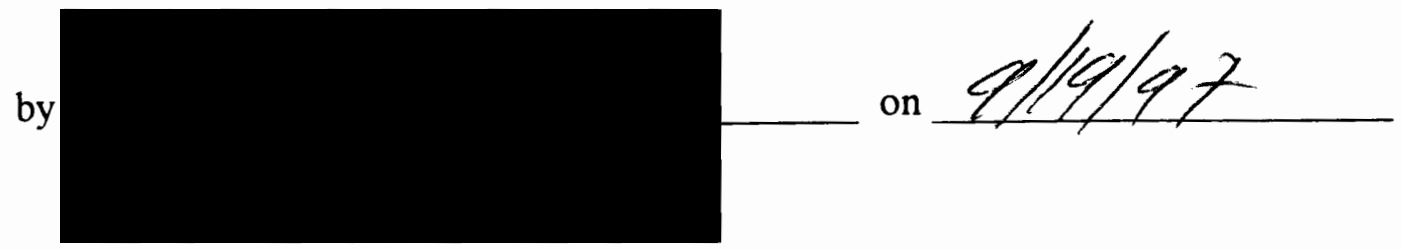
AN ABSTRACT OF THE THESIS OF Emily M. Campbell for the Master of Science in Speech Communication: Speech and Hearing Science presented June $2,1997$.

Title: The Effectiveness of Planned Transitions Therapy in the Treatment of Three Children with Developmental Verbal Dyspraxia.

The intent of this investigation was to note whether use of Planned Transitions Therapy (PTT) would help to improve the intelligibility of 3 children with developmental verbal dyspraxia (DVD). PTT is an approach that emphasizes the sequencing of lingual movements from one place of articulation to the next for the production of speech. Rather than focusing on the production of sounds, exercises with PTT focus on transitions between sounds.

Three male subjects presenting characteristics of DVD received 30-minute treatment sessions with a traditional intervention approach for 6 weeks. Each subject also received periods of intervention with PTT. Subject A received PTT for the entire 6 weeks of intervention; Subject B, for the last 4 weeks; and Subject C, for the last 2 weeks. Intervention with PTT consisted of drills to practice the smooth transitions between sounds. Remediation first focused on transitions from alveolar to velar sounds; then transitions from labial to alveolar to velar sounds; and then velar to alveolar to labial sounds. The clinician used kinetic, visual, and verbal cues to instruct and assist subjects in successful transitions. 
Prior to and following intervention, each subject's percentage of word intelligibility was determined during a 100 -word speech sample. Biweekly probes measuring percentage of word intelligibility were also compared. In addition, preand posttest measures of the number of phoneme errors were obtained through administration of the Goldman-Fristoe Test of Articulation (Goldman \& Fristoe, 1986).

All three subjects demonstrated improvements in percentage of word intelligibility and in the number of phoneme errors. Subject $\mathrm{C}$ demonstrated greater gains than Subjects A and B in percentage of word intelligibility. Subject A demonstrated greater gains in the number of phoneme errors than Subjects B and C. Subject B demonstrated the least gains in both measures. He made minimal gains in intelligibility following treatment with and without PTT. Subject C showed greater gains in intelligibility during treatment with PTT than during treatment with traditional articulation intervention alone. Findings suggest that treatment with PTT in conjunction with traditional articulation intervention was effective in the treatment of Subjects A and C. 
THE EFFECTIVENESS OF PLANNED TRANSITIONS THERAPY

IN THE TREATMENT OF THREE CHILDREN WITH

DEVELOPMENTAL VERBAL DYSPRAXIA

by

EMILY M. CAMPBELL

A thesis submitted in partial fulfillment of the requirements for the degree of

MASTER OF SCIENCE

in

SPEECH COMMUNICATION:

SPEECH AND HEARING SCIENCE

Portland State University

1997 


\section{ACKNOWLEDGMENTS}

First, I want to thank my thesis committee for all of their guidance. Mary Gordon-Brannan is an excellent editor who diligently polished this thesis. In addition, she is a superb professor and I value the instruction she has given.

I want to recognize Charlene Clark for authoring the idea for this study and giving direction and encouragement in its execution. Apart from this study, she has been an excellent role-model and has assisted in honing my clinical skills in the evaluation and treatment of child articulation disorders.

As my advisor and professor, John Tetnowski has helped me to construct a strong educational foundation to support my clinical work. I greatly appreciate the knowledge he has shared and want to thank him for the insight he has given to this study.

I want to recognize Jeanie Edwards for taking leave from retirement to serve on my thesis committee. Her comments and questions were a pleasure to answer.

Finally, I want to thank Derek Clayton, my dearest friend, for all the encouragement he has given while I pursued my studies; for all of the social gatherings he attended solo; for the support he gave when I was frustrated, and for the celebration he provided when I succeeded. 


\section{TABLE OF CONTENTS}

\section{PAGE}

ACKNOWLEDGEMENTS $\ldots \ldots \ldots \ldots \ldots \ldots \ldots \ldots \ldots \ldots \ldots \ldots \ldots \ldots$

LIST OF TABLES $\ldots \ldots \ldots \ldots \ldots \ldots \ldots \ldots \ldots \ldots \ldots \ldots \ldots \ldots \ldots \ldots$

LIST OF FIGURES $\ldots \ldots \ldots \ldots \ldots \ldots \ldots \ldots \ldots \ldots \ldots \ldots \ldots, v$

\section{CHAPTER}

I INTRODUCTION $\ldots \ldots \ldots \ldots \ldots \ldots \ldots \ldots \ldots \ldots \ldots$

Statement of Purpose $\ldots \ldots \ldots \ldots \ldots \ldots \ldots \ldots, 3$

II REVIEW OF THE LITERATURE $\ldots \ldots \ldots \ldots \ldots \ldots \ldots \quad 5$

Definitions of Terms .................. 5

Characteristics of Developmental Verbal Dyspraxia .....10

Treatment Methods ................... 12

Summary ....................... 18

III METHODS ........................ 20

General Plan .................... 20

Subjects $\ldots \ldots \ldots \ldots \ldots \ldots \ldots \ldots \ldots \ldots \ldots \ldots \ldots \ldots \ldots \ldots$

Procedures $\ldots \ldots \ldots \ldots \ldots \ldots \ldots \ldots \ldots \ldots, 26$

Data Measurement and Analysis ............ 31

IV RESULTS AND DISCUSSION............... 33

Results ...................... 33 
Discussion 41

V SUMMARY AND IMPLICATIONS . 50

Summary $\ldots \ldots \ldots \ldots \ldots \ldots \ldots \ldots \ldots \ldots$

Implications $\ldots \ldots \ldots \ldots \ldots \ldots \ldots \ldots \ldots \ldots$

REFERENCES 54 APPENDIXES 58

A INFORMED CONSENT $\ldots \ldots \ldots \ldots \ldots \ldots \ldots \ldots$

B TRADITIONAL ARTICULATION INTERVETNION PROCEDURES. ..................... 60

C PLANNED TRANSITIONS THERAPY PROCEDURES . . . . 63

D PRE- AND POSTTEST MEASURES ........... 68 
LIST OF TABLES

PAGE

TABLE

1 CHARACTERISTICS OF SUBJECTS A, B, AND C....... 23 
LIST OF FIGURES

PAGE

TABLE

1 PERCENT OF WORD INTELLIGIBILITY FOR SUBJECT

A OVER THE INTERVENTION PERIOD . . . . . . . . . 34

2 PERCENT OF WORD INTELLIGIBILITY FOR SUBJECT

B OVER THE INTERVENTION PERIOD . . . . . . . . . 35

3 PERCENT OF WORD INTELLIGIBILITY FOR SUBJECT

C OVER THE INTERVENTION PERIOD . . . . . . . . 35

4 COMPARISON OF EACH SUBJECTS' PERCENT

IMPROVEMENT OF WORD INTELLIGIBILITY . . . . . . 36

5 COMPARISON OF PERCENT IMPROVEMENT OF

WORD INTELLIGIBILITY FOR SUBJECTS OVER THE

PERIOD OF TREATMENT WITH PTT $\ldots \ldots \ldots \ldots \ldots \ldots . \quad 37$

6 PERCENT IMPROVEMENT OF WORD INTELLIGIBILITY FOR SUBJECT A TAKEN FROM BIWEEKLY PROBES . . . . 38

7 PERCENT IMPROVEMENT OF WORD INTELLIGIBILITY FOR SUBJECT B TAKEN FROM BIWEEKLY PROBES . . . 39

8 PERCENT IMPROVEMENT OF WORD INTELLIGIBILITY FOR SUBJECT C TAKEN FROM BIWEEKLY PROBES . . . 40 
9 COMPARISON OF DECREASE IN THE NUMBER OF PHONEME ERRORS FOR SUBJECTS ON THE GOLDMANFRISTOE TEST OF ARTICULATION . . . . . . . . 41 


\section{CHAPTER I}

\section{INTRODUCTION}

Apraxia of speech is defined by Bernthal and Bankson (1993) as "an impairment of motor speech programming with no weakness, paralysis, or incoordination of the speech musculature" (p. 173). This disorder affects articulatory abilities due to a dysfunction of neural-motor programming for speech. The most noticeable characteristic of apraxia is poor volitional movement needed for speech that causes an impairment in the sequencing of sounds and syllables (Darley, Aronson, \& Brown, 1975). This poor ability to sequence movement of the articulators is marked by noticeable struggle and groping and becomes worse as syllable and word length increase (Rosenbek \& Wertz, 1972). Developmental verbal dyspraxia (DVD) is the childhood version of this disorder.

Much controversy exists as to the presence of DVD and to the etiology and characteristics of this disorder. This controversy leads to wide diversity concerning the type of intervention approach needed. Many professionals have cited the need for research in the area of DVD intervention as a means of alleviating this disagreement. Bernthal and Bankson (1993) stated that "one way to support the presence of a diagnostic category is to demonstrate that particular remediation procedures are effective in ameliorating certain symptoms" (p. 177). They noted the importance of documenting progress in response to particular 
intervention procedures as a functional way to test the usefulness of the program. They stated that single subject research designs can be helpful in this regard.

Children with DVD present highly unintelligible speech marked by difficulty in sound sequencing. Although many approaches to the remediation of DVD have taken this lack of ability into consideration, none has been subject to rigorous experimental investigation (Square, 1994). Clark (personal communication) designed Planned Transitions Therapy (PTT) for children who present sequencing difficulties (C. E. Clark, personal communication, October 24, 1995). Although it has been used in a clinical setting with noted subjective success, investigation has not been conducted to demonstrate empirically its effectiveness. In a PTT approach, the smooth transitions between sounds are emphasized; however, PTT differs in that the focus is on the transitions between phonemes based upon their place of articulation. For example, drills emphasize movement sequences from alveolar to velar sounds, and from bilabial to alveolar to velar sounds. In addition to this characteristic of PTT, a multisensory approach in the elicitation and stabilization of correct sound productions is used. Motokinesthetic, visual, and verbal models and cues are used in the instruction and as reminders of the movements that are required to produce sound sequences. Presence of these properties suggests that use of PTT may provide an effective intervention approach for children presenting with DVD. 
Statement of Purpose

The purpose of this study was to examine the effectiveness of using PTT in addition to traditional articulation intervention in the treatment of 3 children who present with DVD. The research question posed was: Is the use of PTT in conjunction with traditional articulation intervention more effective in treating clients presenting with DVD than treatment with traditional articulation intervention alone? This was a single-subject study using a multiple-baseline across subjects design to measure the effects of remediation with PTT.

During this study, 3 subjects received PTT at differing intervals throughout the intervention period. Subject A received PTT for 6 weeks of intervention. Subject B received PTT for 4 weeks and Subject C received PTT for 2 weeks. Hypothesis 1 was: Inclusion of PTT results in a greater percentage improvement of word intelligibility than treatment with traditional articulation intervention alone. It was postulated that following intervention with PTT Subject A would show greater percent improvement of word intelligibility than the Subject B and Subject B would show greater improvement than Subject C.

Hypothesis 2 was: Inclusion of PTT results in a greater decrease in the number of phoneme errors on the Goldman-Fristoe Test of Articulation (Goldman \& Fristoe, 1986) than treatment with traditional articulation intervention alone. The investigator postulated that, concluding intervention, Subject A would show a 
greater decrease in the number of phoneme errors than Subject B and Subject B would show a greater decrease than Subject $C$. 


\section{CHAPTER II}

\section{REVIEW OF LITERATURE}

\section{Definitions of Terms}

Beschwing (as cited in Crary, 1984) defined apraxias in 1975 as "disorders of the execution of learned movement which cannot be accounted for either by weakness, incoordination, or sensory loss, or by incomprehension of or inattention to commands" (p. 33). Apraxias can be differentiated from dysarthrias because they do not involve impairment in muscle tone or strength. Apraxia is a disorder that impairs a person's ability to perform volitional tasks, rather than automatic tasks, due to dysfunction of neural-motor programming (Bernthal, \& Bankson, 1993).

Apraxia has been subdivided into various types, developmental verbal dyspraxia (DVD) being one of these. Also included in the category of apraxia are oral apraxia, limb apraxia, and acquired verbal dyspraxia. Darley, Aronson, and Brown (1975) defined verbal dyspraxia as an impairment of the central motor programming for the voluntary production of phonemes and the sequencing of muscle movements for the production of words. Children with this disorder display a breakdown at the level of articulatory planning. They show difficulty in retrieving the commands to perform movements needed in producing particular sounds and sequences of sounds. 
The disorder under review has been identified by many terms since it was first recognized in the 1900s. At that time, Collier termed it congenital maladroitness (Cermak, 1985). Today, many terms are used interchangeably with DVD, including developmental articulatory dyspaxia, verbal dyspraxia, childhood dyspraxia, and developmental apraxia of speech (Aram, 1984). The term developmental is used to differentiate this disorder from its adult counterpart, acquired verbal dyspraxia. It is important to note that DVD and acquired verbal dyspraxia are different disorders with varying etiologies and characteristics, and different approaches should be taken during assessment and intervention. When using the term acquired verbal dyspraxia, it is assumed that damage to the brain has occurred after the person has attained the speech and language skills needed for communication. Adults have the experience of many years in which to habituate the motor sequences used in volitional tasks. Conversely, because their disorder is congenital or the lesion occurred before the onset of speech development, children with DVD have difficulty acquiring adequate motor skills needed to perform these tasks. Cermak (1985) explained that children with DVD have a difficult time learning and performing newly learned motor-speech tasks. Unlike their adult counterparts, they have not had the years of use needed to establish sets of sequential patterns.

It is rare to find DVD in its pure form. It is often found in combination with oral apraxia (Bernthal \& Bankson, 1993; Blakeley, 1980; Chappell, 1973; 
Rosenbek \& Wertz, 1972). According to De Renzi, Piezuro, and Vignolo (1966), oral apraxia is an impairment in the performance of voluntary movements involving muscles of the larynx, pharynx, tongue, lips, palate, and cheeks, although automatic movements of the same musculature appear to be unimpaired. Whereas DVD impairs a child's ability to use articulators voluntarily during speech acts, oral apraxia affects a person's skills in movement of the oral musculature for the performance of nonspeech acts. With oral apraxia, there is a potential for speech difficulty. For example, poor timing of movement and lack of closure of the soft palate can cause resonance abnormalities as well as articulation disorders. It is important to note that oral apraxia and DVD are two distinct disorders. Assessment of a child should include evaluation of the child's ability to move articulators voluntarily during both speech and nonspeech tasks. Treatment should not focus on just oral training to enhance muscle movement, but on the sequencing of movements needed to produce speech (Crary, 1984).

Whereas sites of lesions can be determined in acquired apraxia, the causes of DVD are not known (Chumpelik, 1984). Some postulate that diffuse damage occurs that results in multiple small lesions. These cortical lesions are thought to cause a breakdown in voluntary motor planning and sequencing. There are various theories behind this breakdown. Chumpelik explained that there are two systems that enable a person to perform muscle movements, including a closedloop system and an open-loop system. According to Chumpelik, some researchers 
believe that programming is regulated by a closed-loop system in which all adjustments are made before the signal is sent to the muscles. Damage to this system would diminish a child's ability to establish a motor plan for speech production. Other researchers believe that the open-loop system is affected in DVD (Square, 1994). Kinesthetic and proprioceptive feedback from the speech structures are not processed normally. This results in diminished ability to prepare movements appropriately and reduced ability to guide the sequencing of muscle contractions. Poor feedback in children makes it difficult for them to learn appropriate motor programs. This suggests that DVD is a disorder of speech motor control based on poor development of speech motor programs.

Chumpelik (1984) postulated that movements are regulated by a combination of both the closed- and open-loop systems. She proposed that higher levels of the nervous system determine the timing and movements toward the place of articulation, and feedback from the lower motor neurons aids with adjustment for detail and production of sequences. Principles of open- and closed-loop systems are central to many of the techniques used in remediation of DVD that emphasize the use of multisensory awareness in teaching sequences of movements.

Discussion of DVD in the literature is encompassed by controversy. The etiology and characteristics of DVD, not to mention its very existence as a separate disorder from functional articulation disorders, is questioned by many 
professionals (Hall, 1992; Stackhouse, 1992; Stackhouse \& Snowling, 1992). Many dispute whether the underlying dysfunction is related to output motor processes or phonological representations. Marion, Sussman, and Marquardt (1993) found that children with DVD have inferior abilities in rhyming words than those without DVD. They suggest that DVD is a fundamental disorder at the segmental phonological level of language that influences all components of language. Crary (1984) is also a believer that DVD is a widespread linguistic impairment. He explained that, because children have not yet acquired language skills needed to communicate, disorder of their phonological system affects their use of syntactical markers and forms. A linguistic theory suggests that phonological properties form a bridge between grammatical organization and the motoric/acoustic realities of speech production.

On the other hand, others dispute that DVD is a linguistic disorder explaining that it is caused by a deficit in senso-motor integration. Blakeley (1980) stated that DVD is a nonlinguistic disorder. He views it as a disorder that impairs the programming to position speech musculature and the sequencing of muscle movements for volitional actions. A study performed by Groenen, Maassen, Crul, and Thoonen (1996) supported a senso-motoric theory by showing that children with DVD demonstrate a specific relation between auditory processing difficulty and frequency of place-of-articulation substitution errors. Their study suggested that DVD is a disorder of the open/closed-loop system and 
not a deficit in phonetic processing/categorization. The senso-motoric theory supports the rationale for employing intervention that focuses on the sequential transitions of the articulators for speech.

\section{Characteristics of Developmental Verbal Dyspraxia}

Differentiating between DVD and functional articulation disorders is a difficult task. Much of the controversy surrounding DVD is due to disagreement about the many characteristics of this disorder and how these differ from other impairments of articulation. There are only a few researchers who pinpoint the phonological characteristics of DVD. These were summarized by Crary in 1984. The major impairment of children in DVD is decreased intelligibility that is marked by errors in articulation manifested by omissions (most prominent), substitutions, additions, and distortions of consonants and vowels. These errors are highly inconsistent as compared to those made by children with functional articulation disorders (Creaghead, Newman, \& Secord, 1989; Rosenbek \& Wertz, 1972; Weiss, Gordon, \& Lillywhite, 1987). Unlike children with functional articulation disorders, children with DVD frequently make errors in vowel production (Rosenbek \& Wertz, 1972).

It has been noted by many sources that children with DVD display poor sequencing of the movements of articulators between sounds and syllables (Blakeley, 1980; Chappell, 1973; Rosenbek, Hansen, Baughman, \& Lemme, 
1974; Yoss \& Darley, 1974). This difficulty in sound sequencing results in more articulation errors as syllable and word length increases and the phonological structure becomes more complex (Rosenbek \& Wertz, 1972). For example, a child with DVD will find it more difficult to produce CVC syllables than CV syllables, consonant clusters than consonant-vowel sequences, and polysyllabic words as compared to monosyllabic words (Weiss et al., 1987; Yoss \& Darley, 1974). In their study, Yoss and Darley (1974) noted this poor ability to program sequential movements in that children with DVD displayed slow rates and inconsistent syllable sequencing during diadochokinesis. The significance of this characteristic displayed in children with DVD is of most importance to the rationale behind using an intervention approach that emphasizes the transitions between sounds.

In their review of 50 cases of DVD, Rosenbek and Wertz (1972) noted that these children also demonstrate behaviors of trial-and-error groping that are manifested as dysfluency errors of repetition, prolongation, or silent posturing. Chappell (1973) also observed that these children display effort marked by struggle and groping responses of the articulators.

In addition to phonological characteristics, children with DVD have been noted to display errors in prosody including inappropriate use of rhythm and rate. These children tend to talk at a slower rate with even stress and frequent pausing between syllables and sounds. These impairments in prosody have been 
explained as attempts to compensate for poor articulation and sequencing of oral movements (Rosenbek \& Wertz, 1972; Square, 1994, Weiss et al., 1987; Yoss \& Darley, 1974).

Children with DVD display significantly delayed expressive language skills as compared to receptive language skills (Bernthal \& Bankson, 1993; Blakeley, 1980; Chappell, 1973; Rosenbek \& Wertz, 1972; Yoss \& Darley, 1974) and tend to be resistant to traditional forms of intervention (Blakeley, 1980; Chappell, 1973; Weiss et al, 1987; Winitz, 1984). According to Crary (1984), DVD is predominant among males.

In summary, the speech of children with DVD is characterized by poor intelligibility, omission and substitution errors, additional articulation errors with motorically complex syllables/words, difficulties with sound sequencing, inconsistency of errors, and distortion of vowels. Children with DVD may also display struggle behavior, poor control over prosody, and reduced expressive language skills. Intervention using traditional methods of articulation intervetion result in limited improvement.

\section{Treatment Methods}

The goal of treatment for children with DVD should be to assist them in acquiring volitional speech that is as near to normal as their physiological conditions will permit (Rosenbek et al., 1974). The child with dyspraxia may 
adequately produce automatic, reflexive gestures and sounds, but have difficulty when requested to produce sounds; therefore, intervention should focus on enhancing volitional movement skills for speech to improve intelligibility. Intervention approaches that are traditionally used with children presenting with functional articulation disorders have not been found to be beneficial when working with children who have DVD (Blakeley, 1983, Weiss et al., 1987). These types of interventions focus on the production of phonemes by emphasizing their place of articulation. Review of the literature suggests that the most significant symptom of DVD is deviant sequencing of movements; therefore, the appropriate treatment might emphasize the transitions between sounds as a means of enhancing sequencing for speech production. Approaches to the treatment of DVD that are currently advocated use sensory-awareness techniques and focus on good transitions of the articulators, and prosodic control of speech. Following is a review of the literature with regard to treatment approaches for DVD; however, empirical evidence to support the use of these approaches is lacking. There have been no comparative studies to determine the effectiveness of these treatment techniques or the effects of one technique over another in the treatment of children with DVD. 
Multisensory Training

Taking into account the theory that children with DVD may have established deviant motor programs due to a lack of kinesthetic and proprioceptive feedback (Chumplik, 1984), there are many treatment techniques that involve enhancement of kinesthetic awareness for movement sequences. This is accomplished by heightening sensory input during drills of movement transitions; brushing sandpaper, cotton, or other textures across the lips and inside the mouth help to stimulate the oral-sensory mechanisms (Haynes, 1985). Deep pressure and resistance techniques such as those used in the Touch Cue system (Bashir, Grahamjones, \& Bostwick, 1984), the Prompts for Restructuring Oral Muscular Phonetic Targets (Chumpelik, 1984), and the Adapted Cueing Technique (Klick, 1985) have also been used to increase postural awareness. Methods that employ the use of visual and auditory input have also been reported to be effective when working with children who have DVD. Yoss and Darley (1974) have advocated the use of oral exercises, including mirror work, and imitation of precise placement of the articulators. Use of the mirror may stimulate visual awareness of articulatory positioning that incorporates tongue and lip movements. Chappell (1973) stated that "a few severely involved children may require a more demanding strategy involving assistive phonetic placement and movement of the child's articulators by the clinician" (p. 365). She cited the motokinetic approach as developed by Young and Hawk (1955). Techniques of 
multisensory stimulation have been advocated in facilitating postural awareness of the articulators, and many such programs have been developed.

\section{Prosodic Intervention}

A variety of techniques are available that focus on prosody and are used with persons displaying varying types of disorders. Square (1994) noted many that have been useful in working with children who present with DVD. Because prosody has been noted to be impaired in children with DVD, remediation often focuses on regulating rate and melodic flow. Rate Control Therapy (Rosenthal, 1994) includes both techniques of decreasing and increasing rate. Altering rhythm, tempo, and pitch has also been used as a means of achieving normal prosody (Helfrich-Miller, 1994). In some approaches, motor movements such as arm swinging, and foot and finger tapping have been paired with vocalizations to cue the prosodic quality of speech (Haynes, 1985; Square, 1994). According to Weiss et al. (1987), it is useful to teach even stress and pauses in polysyllabic words and sentences, to slow the speaking rate by prolonging vowels, and to use the intrusive schwa in blends. Many of these techniques serve to facilitate intelligibility by slowing down speech. Slow rate may facilitate good productions by providing the impaired system with enough time to process kinesthetic and proprioceptive feedback and to make appropriate neuromotor adjustments to the speech musculature. These techniques may also help children to learn movement 
patterns more effectively. Phonemes are held in place long enough to allow feeling of the produced posture. These postures can be compared to postures that are already established in the motor programmer and correct placements can be inputted (Square, 1994).

\section{Sound Sequencing}

In treatment approaches with children presenting with DVD, movement sequences most often are emphasized regardless of the severity of the apraxia. Because this disorder affects ability to perform sequences of movements, activities focus on transitions between sounds, rather than the placement of articulators to produce sounds. Syllables have been taught as a means of improving skills in sequencing patterns of sounds. Emphasis has been placed on consonant-vowel, vowel-consonant, and consonant-vowel-consonant sequences in syllables, followed by these productions in words and phrases. Many children with DVD demonstrate difficulty in producing vowels as well as consonants. If this is the case, vowels are taught early, because the vocalic segment is the core of stimuli used during all further steps of remediation that focus on the sequential patterns of speech. Lessons in sequencing the movement of articulators have been incorporated into intervention by many professionals (Blakeley, 1983; Klick, 1994; Rosenbek et al., 1974; Yoss \& Darley, 1974). 
Planned Transitions Therapy

After finding that intervention using more traditional approaches to the remediation of articulation disorders was not effective when working with children who display DVD, Clark (personal communication, October 24, 1995) began to use a method of intervention that emphasizes the sequencing of movements for the production of speech, an approach labeled Planned Transitions Therapy (PTT). Due to poor ability to sequence movements of the oral musculature to produce speech, this approach focuses on the smooth transitions between sounds and syllables, rather than placement during specific sounds. Through exercises, intervention activities focus on the sequencing of tongue movements from one place of articulation to the next. This approach differs from other sound sequencing methods in that it emphasizes transitions between phonemes based upon their place of articulation. Drill exercises focus on 10 groups of transitions which target movement patterns between alveolar sounds $/ \mathrm{t}$, $\mathrm{d}, \mathrm{n}, \mathrm{l}$, from alveolar to velar sounds $/ \mathrm{k}, \mathrm{g}, \eta /$, from velar to alveolar sounds, and from bilabial /p, b, m, w/ to alveolar to velar sounds. Vowels are used with the consonants to facilitate a speech-like production.

PTT is used in conjunction with either a traditional articulation or phonological approach. Inclusion is accomplished by working on PTT exercises for 5 minutes at various times during a session. Because exercises require 
intensive drill, it has been found that children find it difficult to attend to these activities for a long period of time.

In order to teach and reinforce correct movement, physical assistance and kinetic, visual, and verbal models and cues are employed. These help to enhance the child's sensory awareness and include such techniques as touching the child's face and neck, physically assisting tongue movement with a tongue blade, and verbally coaching during transitions. As mentioned above, multisensory awareness techniques have been found to be facilitative when working with these children.

\section{Summary}

Developmental verbal dyspraxia is a speech disorder that impairs a child's ability to perform volitional movements for speech, most specifically abilities in neuromotor programming. Controversy exists surrounding the etiology and characteristics of this disorder, and the type of intervention that it requires. Traditional approaches to the remediation of articulation disorders have been noted to be ineffectual in aiding children with DVD. There are many treatment approaches that emphasize the sequencing of articulatory movements for speech, but none of these have been subject to experimental investigation. PTT differs from these approaches and may be more effective in its methods of facilitating proper sequencing for speech. This study attempted to determine the effectiveness 
of PTT in conjunction with traditional articulation intervention in the treatment of three children with DVD. 


\section{CHAPTER III}

\section{METHODS}

\section{General Plan}

This study was conducted at the Portland State University Speech and Hearing Clinic in Portland, Oregon. Subjects included 3 males who displayed characteristics of developmental verbal dyspraxia (DVD). This study took place over an 8-week period. Each subject received direct intervention with a traditional articulation approach for 6 weeks. In addition, the subjects received Planned Transitions Therapy (PTT), a method of intervention that emphasizes smooth transitions between sounds. Subject A, 6 years 7 months, received intervention with PTT throughout the entire 6-week period. Subject B, 6 years 2 months, received PTT for the last 4 weeks; and Subject C, 6 years 4 months, received PTT for the last 2 weeks of intervention.

Hypothesis 1 was that inclusion of PTT in the intervention of children with DVD results in a greater percent improvement of word intelligibility than treatment with traditional articulation intervention alone. To test this hypothesis, percent of word intelligibility was obtained prior to and following the 6 weeks of intervention. Measures of the number of phoneme errors were obtained before and after intervention to test hypothesis 2 , which predicts a greater decrease in the number of phoneme errors with incorporation of PTT. These findings, as well as 
biweekly probes, were compared to note any changes in articulatory ability that would indicate the effectiveness of the use of PTT in conjunction with traditional articulation intervention when working with children who display characteristics of DVD as compared to treatment with traditional articulation intervention alone.

\section{Subjects}

Through referral to this investigator by the PSU Speech and Hearing Clinic and the Portland Public School District, 3 males, 6-7 years of age, were selected. Each subject for this study met the criteria outlined below:

1. Displayed characteristics of DVD as described below.

2. Informed consent signed by parent/primary caregiver stating permission for child to participate in, and acknowledging their commitment to, the guidelines of the study (Appendix A).

3. Hearing within normal limits as determined by a pure tone audiometric screening (25dB for the frequencies of $500,1000,2000$, and $4000 \mathrm{~Hz}$ ).

4. A receptive vocabulary standard score on the Peabody Picture Vocabulary Test - Revised (PPVT-R; Dunn \& Dunn, 1981) that was within the average range.

5. A weighted score on the Screening Test for Developmental Apraxia of Speech (Blakeley, 1983) of less than - 60.

6. A percent of word intelligibility during a 100-word spontaneous speech sample that was less than or equal to 75 . 
7. Misarticulation score on the Goldman-Fristoe Test of Articulation (Goldman \& Fristoe, 1986) at or below the fifth percentile.

8. Standard English as the primary language spoken in the home.

9. No concomitant abnormality that was of etiologic significance to the speech disorder such as dysarthria, aphasia, or autism.

The parents/caregivers were given a thorough verbal description of the evaluation and intervention processes prior to their signing of the informed consent and to their child's participation in the study. Subjects did not receive additional articulation or phonological intervention during participation in this study.

The subjects were previously diagnosed with DVD by a professional speech-language pathologist holding the Certificate of Clinical Competence before being referred to this investigator. To determine the presence of characteristics associated with DVD, subject assessment was performed by the investigator. Subject assessment included a sampling of speech and administration of the Screening Test for Developmental Apraxia of Speech and the Goldman-Fristoe Test of Articulation. For inclusion, the children had to demonstrate the following speech characteristics commonly associated with DVD:

(a) presence of reduced intelligibility, (b) omission and substitution errors, (c) additional articulation errors with motorically complex syllables/words, (d) difficulties with sound sequencing, and (e) inconsistent errors. Subjects could 
also display other characteristics commonly found in children with DVD such as vowel distortions, struggle behavior, poor control over prosody, and reduced expressive language skills. Characteristics of the three chosen subjects are displayed in Table 1.

Table 1

Characteristics of Subjects A, B, and C

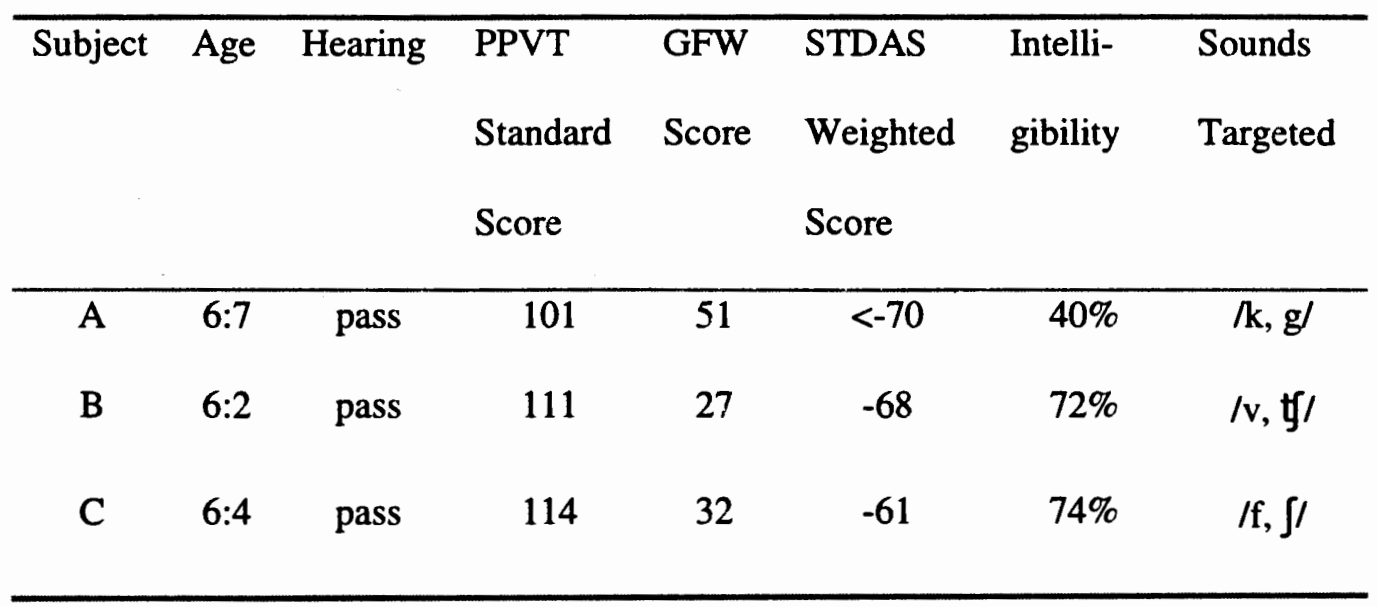

Subject A. Subject A was a 6 year 7 month old male who was referred by the clinic coordinator of the PSU Speech and Hearing Clinic. His hearing was found to be within normal limits as determined by the audiometric screening. On the PPVT-R, he received a standard score of 101 which is average for his age group. Subjct A demonstrated a profound articulation disorder. He produced 51 sound errors on the Goldman-Fristoe Test of Articulation which placed him below the 1st percentile for his age group. His performance revealed errors of 
substitution, distortion, and omission. Although inconsistent, his sound repertoire consisted primarily of $/ \mathrm{d}, \mathrm{p}, \mathrm{b} /$ with occasional productions of $/ \mathrm{m}, \mathrm{n}, \mathrm{t}, \mathrm{s}, \mathrm{t} / \mathrm{He}$ substituted almost all consonant sounds with $/ \mathrm{b}, \mathrm{p}, \mathrm{d} /$ and demonstrated substitution and omission errors for $/ \mathrm{b}, \mathrm{p}, \mathrm{d} / \mathrm{at}$ times. A 100-word speech sample revealed intelligibility at $40 \%$. On the Screening Test for Developmental Apraxia of Speech, this subject received a total weighted score below -70 . He demonstrated difficulty sequencing syllables during diodochokinesis testing. $\mathrm{He}$ made inconsistent sound errors when producing simple words and was unable to repeat words of increased length and complexity. He made vowel distortions and demonstrated groping while attempting to imitate verbal and nonverbal oral-motor tasks.

Subject B. Subject B was a 6 year 2 month old male who was referred to this investigator by a speech-language pathologist in the Portland Public School District. He passed the audiometric screening and received a standard score of 111 on the PPVT-R which indicated receptive vocabulary that was within normal limits. On the Goldman-Fristoe Test of Articulation, Subject B produced 27 sound errors which placed him at the 5th percentile for his age. His performance revealed errors of substitution and omission. His intelligibility during a 100-word speech sample was judged to be $72 \%$. On the Screening Test of Developmental Apraxia of Speech, Subject B received a total weighted score of -68 . He demonstrated struggles and retrials when attempting to imitate verbal and 
nonverbal oral movements. He experienced difficulty during tests of diodochokinesis and was unable to produce triple sequences of three syllables

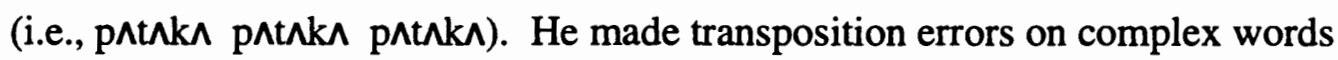
and demonstrated inconsistent errors on recurring words during spontaneous speech.

Subject C. Subject C was a 6 year 4 month old male who was referred for this study by a speech-language pathologist in the Portland Public School District. He passed the auditometric screening and his receptive vocabulary was found to be within normal limits after receiving a standard score of 114 on the PPVT-R. He produced 32 sound errors on the Goldman-Fristoe Test of Articulation which placed him at the 2nd percentile for his age group. His performance revealed errors of substitution, distortion, and omission. His intelligibility was judged to be at $74 \%$ during a 100 -words speech sample. On the Screening Test of Development Apraxia of Speech, Subject C received a total weighted score of -61 . He demonstrated little difficulty imitating nonverbal oral movements, but much difficulty sequencing syllables during tests of diodochokinesis. He made errors in vowel production and made inconsistent sound errors in words during spontaneous speech. Errors occurred more often on words of increased length and complexity. This subject made errors in expressive language, using inappropriate verb tenses during spontaneous speech. 
Procedures

\section{Pre- and Posttest Measures}

To establish a stable baseline, pretest measures of percentage of word intelligibility were taken during three sessions prior to the intervention period. Percent of word intelligibility was measured through the assessment of a 100word speech sample. A tape recorder was used to audiotape each sample during a spontaneous activity. The subjects were instructed to describe pictures and tell a story while looking through the book The Relatives Came (Rylant \& Gammel, 1985). Percentage of word intelligibility for each subject was determined by three students in a master's program of speech-language pathology by listening to the audiotaped samples. These students first familiarized themselves with the stimuli pictures. Each student then transcribed the audiotaped samples marking $\mathrm{X}$ for words that were completely unintelligible. The words on which at least two of the student listeners agreed were rated as intelligible. Words were rated as unintelligible when at least two of the student listeners were not in agreement. Since there were 100 words in each sample, the number of intelligible words for each subject was the same as the percentage of word intelligibility. For each subject, baseline remained stable with ranges of less than $10 \%$ difference in intelligibility. Appendix D displays the pre- and post-test intelligibility measures. Therefore, an average of the pretest measures was used to report results. These 
same procedures were performed to obtain posttest measures. Biweekly probes were performed using additional pictures from The Relatives Came to help determine whether or not the inclusion of PTT assisted in increasing intelligibility. During biweekly probes 100-word samples were collected for each subject following the procedures outlined above.

Both prior to and following intervention, the number of phoneme errors was determined through administration of the Goldman-Fristoe Test of Articulation. To test hypothesis 2 , the number of errors for Sounds-in-Words was determined by the same three graduate students by following the test protocol while listening to an audio-taped sample. The students listened to the samples and judged whether or not specific sounds were in error. The total number of phoneme errors consisted of sounds judged by at least two of the student listeners to be in error.

\section{Intervention}

Each subject participated in two 30-minute sessions per week for 6 weeks. A traditional approach to remediation that emphasized the place and manner of specific phonemes focused on the child's specific misarticulations as determined by the Goldman-Fristoe Test of Articulation. Activities included picture cards and manipulatives. The type of approach remained constant for each subject; however, intervention focused on different phonemes (Table 1). Phonemes were 
chosen based on typical order of acquisition. Traditional intervention with Subject $A$ focused on the production of $/ \mathrm{k}, \mathrm{g} /$ in the initial position of $\mathrm{CV}$ and CVC syllable words. Subject B received traditional intervention with emphasis on the production of $/ v /$ and $/ t /$ in words, phrases, and sentences. Subject $C$ received traditional articulation intervention that targeted the production of $/ f /$ and /J/ in words, phrases, sentences, and spontaneous speech. An outline of procedures for the traditional approach used is presented in Appendix B.

PTT is a procedure that involves working on the sequencing of tongue movement from one place of articulation to the next for the production of speech. Exercises focus on the transitions between sounds, rather than the production of particular sounds. Subject A received PTT throughout the entire 6-week intervention period. Subject B received PTT for the last 4 weeks and Subject C received PTT for the last 2 weeks of intervention. PTT drills were performed for 5 minutes at the beginning, approximately 15 minutes into, and at the conclusion of each session.

Activities used in the intervention with PTT were clinician-directed and consisted of drills to exercise the smooth transitions between sounds. The clinician gave subjects motokinesthetic, visual, and verbal models and cues. Motokinesthetic models and cues included touching the subjects' face and neck to provide reminders of tongue placement, and using tongue depressors to direct manually the tongue to proper positions. To ensure that the subjects were using 
their tongues to perform all of the movements, and were not receiving assistance from jaw motion, the jaw was stabilized by placing $1 / 2$ of a tongue depressor between the subject's molars when needed. Visual models and cues were included by directing the subjects' attention to the clinician's mouth and tongue placement, and using hand motions to remind the subject about proper movement. The clinician gave verbal models and cues by producing good transitions, and by stating directions and reminders of correct movement patterns. Models and cues were reduced as the clinician judged appropriate to facilitate generalization of the transitions. Tangible reinforcement was given as a means of extrinsic motivation. Reinforcement material was chosen based on each subject's interest.

Intervention with PTT consisted of 10 groups of transitions that targeted movement patterns: (a) between alveolar sounds, (b) from alveolar to velar sounds, (c) from velar to alveolar sounds, and (d) from bilabial to alveolar to velar sounds. Groups are outlined in Appendix C only to establish a logical progression. These groups were changed or interchanged as the clinician judged appropriate. There was no criterion for movement from one step to the next. During sessions, at least two types of movement patterns from the 10 groups of transitions were targeted. The number of types of transitions targeted per session was slowly increased as proficiency increased. Vowels and a diphthong /e, i, al, o, $\mathrm{u} /$ were used to facilitate smooth movements between consonants. The subjects 
were instructed to aim for accuracy of smooth transitions and not for speed of tongue movement.

The first step of remediation with PTT focused on the use of transitions between the alveolar sounds $/ \mathrm{t} /$ and $/ \mathrm{d} /$, and then between the alveolar sounds $/ \mathrm{n} /$ and $/ /$. (If $/ /$ was not in a subject's repertoire, the consonant $/ n /$ was incorporated into movements from $/ t /$ and $/ d /$.) The following steps emphasized movement patterns between alveolar sounds /t, $d, n, l /$ and velar sounds $/ g, k, \eta /$ As proficiency increased with the sequences listed above, transitions that targeted movements from the bilabial sounds $/ \mathrm{p}, \mathrm{b} /$ to the alveolar sound $/ \mathrm{t} /$ to the velar sounds $/ \mathrm{k}, \mathrm{g} /$ were incorporated. (See Appendix $\mathrm{C}$ for procedures to intervention with PTT.)

Each subject was required to complete 5 minutes of daily practice at home with their parents/caregivers. When the subjects were receiving treatment with the traditional method of articulation intervention alone, they were given picture cards of words containing the target sound(s) for the previous session. The parents/caregivers were instructed to play games such as Concentration or Bingo with their children as a means of stabilizing the correct phoneme productions and generalizing them to other environments. When the subjects were receiving intervention using PTT, they were required to practice the specific sound sequences targeted during the previous treatment session. The parents/caregivers were given lists containing the transitions to be emphasized during home practice. 
They were instructed on how to elicit the correct transitions through observation 31 of their child's interaction with the clinician and through direct instruction. Each subject was given a calendar on which to record if they completed their daily homework. For each day they practiced their skills at home, they received a stamp or sticker on their calendar.

\section{Data Measurement and Analysis}

Concluding intervention, posttesting was conducted. Speech samples were obtained over three sessions and percentage of word intelligibility was derived. In addition, the number of phoneme errors was determined through administration of the Goldman-Fristoe Test of Articulation.

Pre- and posttest measures of percentage of word intelligibility and biweekly percentages were compared for each subject to determine whether or not there was an increase in intelligibility. The pretest percentages were then subtracted from the posttest percentages and divided by the possible percent of improvement to obtain a percent improvement of word intelligibility.

To test hypothesis 1 , comparisons were made between the percent improvement of word intelligibility for each subject. Comparison between the subjects' percent improvement was visually displayed using a bar graph. If Subject A showed greater increase in percent of improvement than Subject B, and 
Subject B showed greater increase than Subject C, then the hypothesis was accepted.

To test the hypothesis 2 , results from the pre- and posttest measures of the number of phoneme errors were compared for each subject. By subtracting posttest measures from pretest measures, a decrease in the number of phoneme errors for each subject was derived. Then comparisons were made between the number of phoneme errors for each subject by plotting the results on a bar graph. If Subject A showed greater decrease in the number of phoneme errors in Soundsin-Words on the Goldman-Fristoe Test of Articulation than Subject B, and Subject B showed greater decrease than Subject C, then the hypothesis was accepted.

For additional information, brief parent interviews were conducted to note if the subjects had generalized any of the skills learned to other environments. In addition, percentages derived through the administration of biweekly probes were compared to note any change in percent of word intelligibility that indicated the significance of the use of PTT within the remediation process. 


\section{CHAPTER IV}

\section{RESULTS AND DISCUSSION}

\section{Results}

The research question posed was: Is the use of Planned Transitions Therapy (PTT) in conjunction with traditional articulation intervention more effective in treating clients presenting with developmental verbal dyspraxia (DVD) than treatment with traditional articulation intervention alone?

\section{Pre- and Posttest Measures}

Three subjects (Subjects A, B, and C) presenting with DVD completed 6 weeks of intervention using traditional articulation treatment. In addition, PTT was incorporated in the intervention of these subjects during all or a portion of the treatment period. Subject A was treated with PTT during the entire 6-week intervention period. Subject B was treated with PTT during the final 4 weeks and Subject $\mathrm{C}$ was treated with PTT during the final 2 weeks of intervention.

Percent of Word Intelligibility. Word intelligibility measures were taken prior to and at the conclusion of the 6-week intervention period. In addition, biweekly probes were administered. Each subject's percent of word intelligibility was determined by comparing transcriptions from three graduate students in speech-language pathology. Percent improvement was then derived by 
subtracting the pretest measure from the posttest measure and dividing by the total possible percent improvement. During pre-testing, Subject A who received 6 weeks of PTT demonstrated percent of word intelligibility to be $39 \%$. During the first 2 weeks, his word intelligibility increased to $45 \%$ and then decreased to $43 \%$ after 4 weeks. Posttest measures indicated word intelligibility to be $49 \%$. The $10 \%$ change represents a $16 \%$ improvement $(.49-.39 / .61=.16)$. Figure 1 displays a line graph of changes in percent of word intelligibility for Subject A.

\section{Percent of \\ Word \\ Intelligibility}

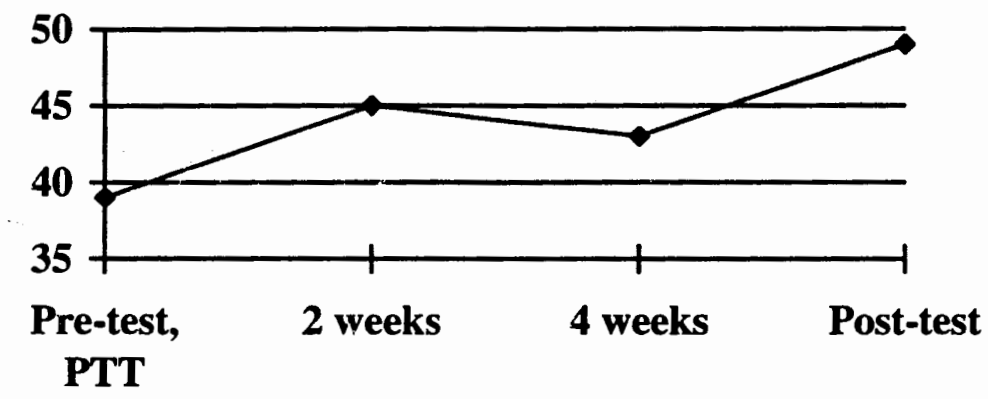

Begins

Figure 1. Percent of word intelligibility for Subject A over the intervention period.

During pre-testing, Subject B who received 4 weeks of PTT demonstrated percent of word intelligibility to be $73 \%$. His percent of word intelligibility increased to $75 \%$ after the first 2 weeks and decreased to $64 \%$ after 4 weeks. During post-testing, his word intelligibility was judged to be $76 \%$ which represents an $11 \%$ improvement $(.76-.73 / .27=.11)$. Figure 2 displays a line graph of changes in percent of word intelligibility for Subject B. 


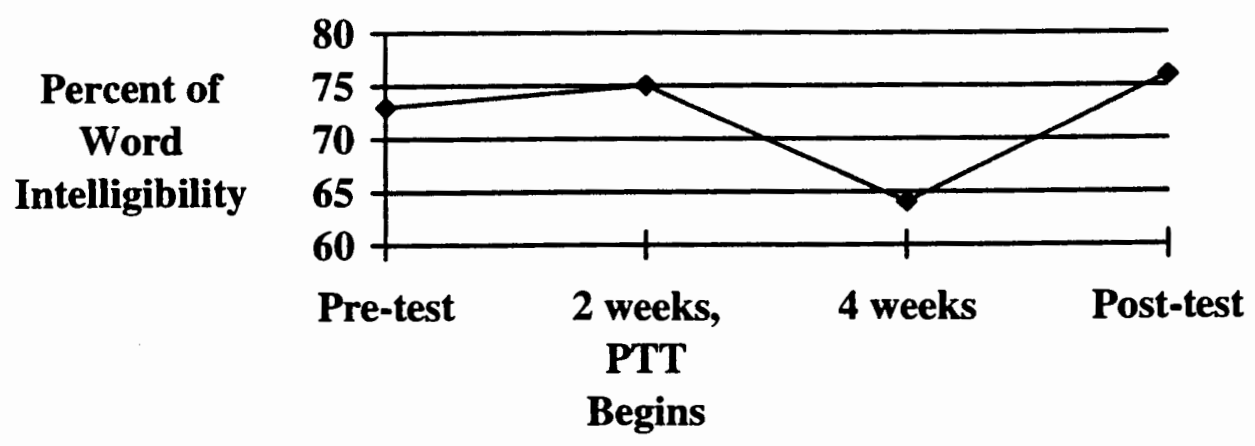

Figure 2. Percent of word intelligibility for Subject B over the intervention period.

During pre-testing, Subject $C$ who received 2 weeks of PTT demonstrated word intelligibility to be $74 \%$. His percent of word intelligibility increased to $76 \%$ after 2 weeks and to $78 \%$ after 4 weeks of intervention. Post-testing revealed percent of word intelligibility to be $82 \%$, representing a $31 \%$ improvement $(.82$ $.74 / .26=.31$ ). Figure 3 displays a line graph of changes in percent of word intelligibility for Subject C.

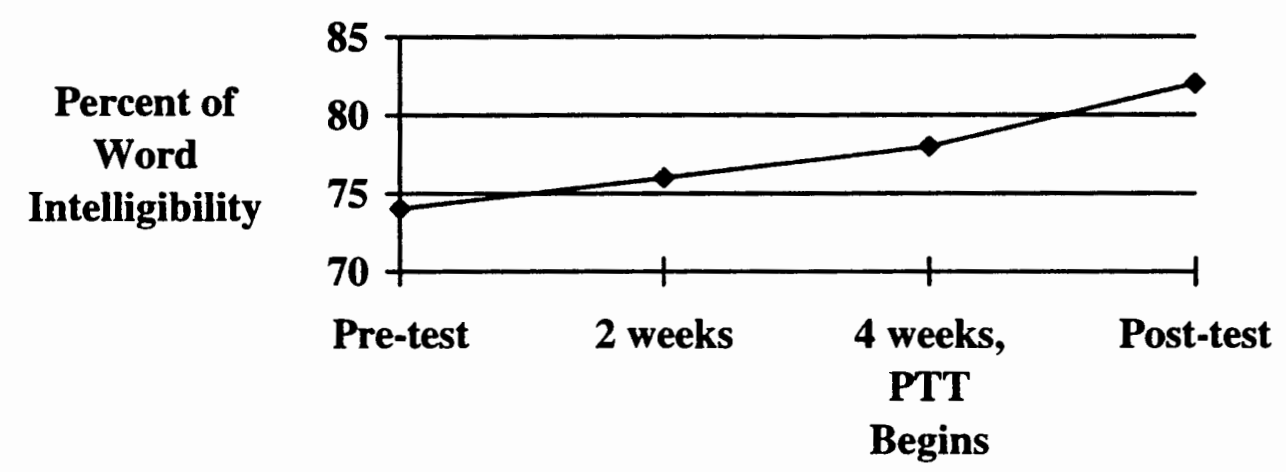

Figure 3. Percent of word intelligibility for Subject $\mathrm{C}$ over the intervention period. 
To test hypothesis 1, that inclusion of PTT into the intervention of children with DVD would result in a greater percent improvement of word intelligibility than treatment with traditional articulation intervention alone, a comparison was made between the percent improvement of word intelligibility for each subject. Figure 4 displays a bar graph for comparison of these measures. The results show that Subject A's word intelligibility improved by 16 percentage points over the entire intervention period. Subject B's word intelligibility improved by 11 percentage points and Subject C's improved by 31 percentage points. The biweekly probes for each subject were compared to note any change in percent of word intelligibility that indicated the significance of the use of PTT within the remediation process. Findings were inconclusive and revealed no clear patterns of change.

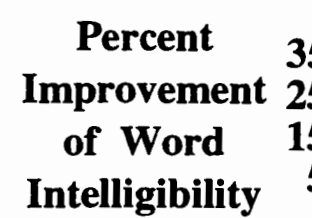

Figure 4. Comparison of each subjects' percent improvement of word intelligibility. 
Measures taken during biweekly probes were used to compare improvement in intelligibility for each subject over the time period during which they received PTT. Figure 5 displays a bar graph for comparison of these measures. The graph displays significant improvement in percentage of word intelligibility for Subject A (16\%) and Subject C (18\%) following intervention with PTT. Subject A received PTT for the entire 6-week period and Subject C received PTT for the last two weeks of intervention. Gains made by Subject B, who received PTT for 4 weeks, were minimal (4\%).

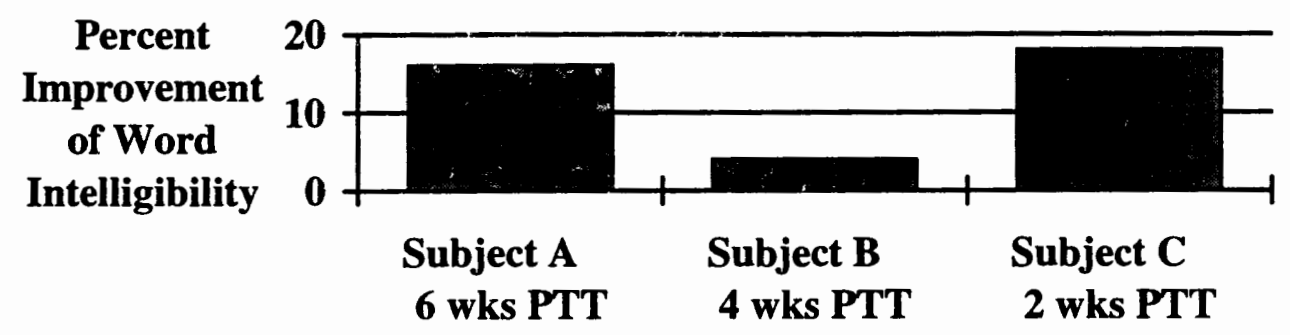

Figure 5. Comparison of percent improvement of word intelligibility for subjects over the period of treatment with PTT.

Figure 6 displays changes in percent improvement of word intelligibility for Subject A. This subject, who receive PTT for the entire 6-week intervention period, made gains (10\%) during the first 2 weeks of treatment with PTT. During the second 2 weeks of treatment with PTT his percent improvement of word 
intelligibility decreased (-4\%). It increased again during the final 2 weeks of intervention with PTT (11\%).

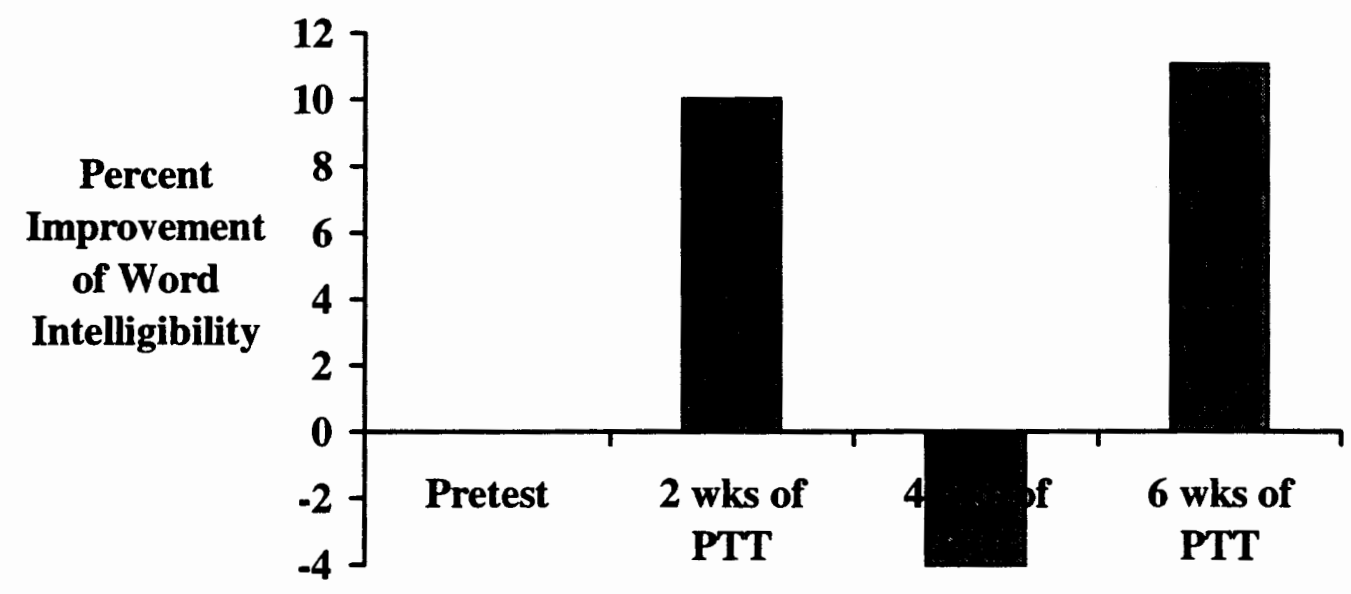

Figure 6. Percent improvement of word intelligibility for Subject A taken from biweekly probes.

Gains in percent improvement of word intelligibility for Subject B are displayed in Figure 7. During the first 2 weeks of treatment with traditional articulation therapy alone, this subject made gains (7\%). A probe taken during the fourth week of intervention, after 2 weeks of treatment with PTT, indicated a decrease in intelligibility (-44\%) followed by an increase (50\%) after the 6-weeks of intervention. 


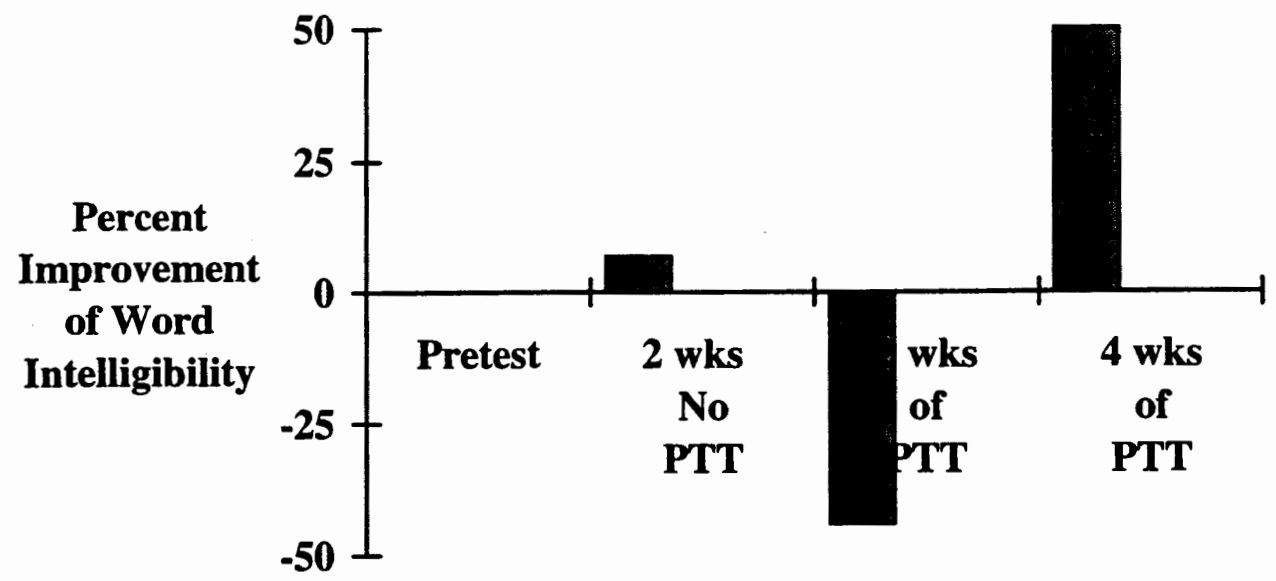

Figure 7. Percent improvement of word intelligibility for Subject B taken from biweekly probes.

Subject $\mathrm{C}$ demonstrated greater percent improvement of word intelligibility during the 2 weeks of intervention with PTT than during intervention with traditional articulation intervention alone. Figure 6 displays gains made by Subject $\mathrm{C}$ during the intervention period. Biweekly probes taken after 2 weeks and 4 weeks of treatment with traditional articulation intervention alone revealed $8 \%$ improvement, respectively. After treatment with PTT an $18 \%$ improvement was achieved. 


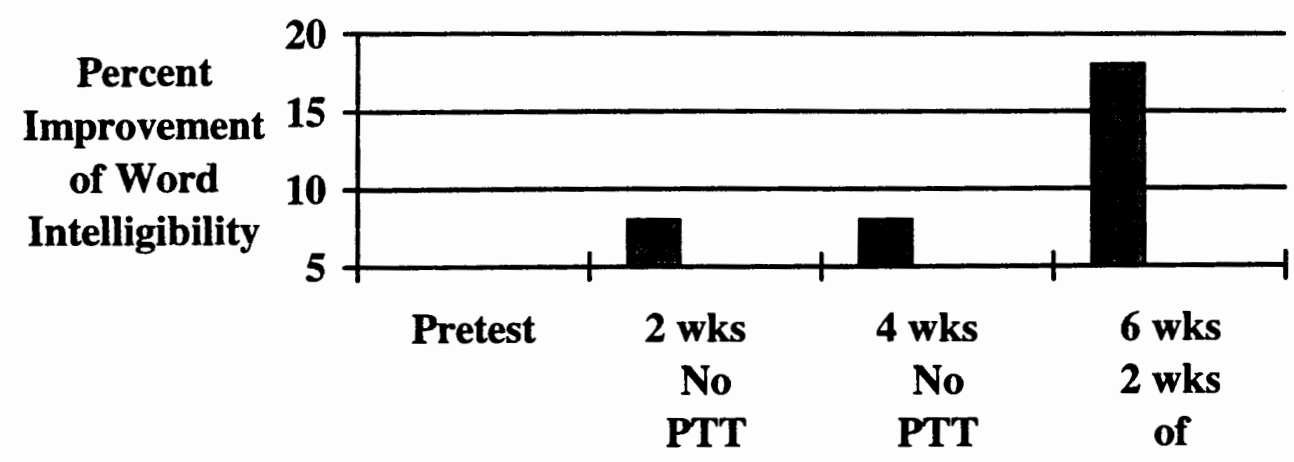

Figure 8. Percent improvement of word intelligibility for Subject $\mathrm{C}$ taken from biweekly probes.

Figures 6 and 8 display gains made by Subjects A and B during the first two weeks of treatment with PTT. Subject B's intelligibility did not improve during the first 2 weeks of treatment with PTT, but improved again following 2 more weeks of intervention with this approach.

Number of Phoneme errors. Each subject was administered the Soundsin-Words subtest of the Goldman-Fristoe Test of Articulation (Goldman \& Fristoe, 1986) prior to and after the 6 weeks of intervention. During pre-testing, Subject A produced 56 sound errors which decreased to 52 during post-testing. Subject B produced 24 sound errors during pre-testing and 22 errors during posttesting. Subject $\mathrm{C}$ produced 25 sound errors during pre-testing and 22 errors during post-testing. 
To test hypothesis 2 , that there would be a greater decrease in the number of phoneme errors with incorporation of PTT, pretest measures were subtracted from posttest measures to determine a decrease in the number of phoneme errors. Figure 7 displays a comparison of this decrease for each subject. Subject A demonstrated a decrease in the number of phoneme errors of 4 points. Subject B demonstrated a decrease of 2 points and Subject $C$ demonstrated a decrease of 3 points. Although Subject A made the most gains, findings do not reveal conclusive evidence about the effectiveness of PTT in conjunction with traditional articulation intervention.

\section{Decrease in the \# of Phoneme} Errors

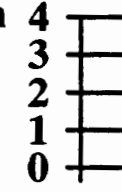

Subject A 6 wks PTT

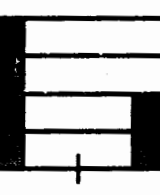

Subject B 4 wks PTT

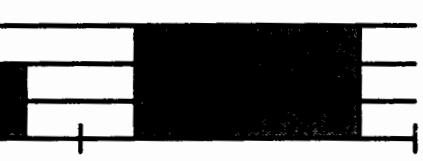

Subject C 2 wks PTT

Figure 9. Comparison of the decrease in the number of phoneme errors for subjects on the Goldman-Fristoe Test of Articulation.

\section{Discussion}

Discussion of this study begins with a synopsis of the intervention and findings for each subject. Then comparisons will be made between each subject's gains in percentage of word intelligibility and the number of phoneme errors. 
This section will close with discussion of the conclusions made about the effectiveness of PTT in addition to traditional articulation intervention.

\section{$\underline{\text { Subject A }}$}

Subject A's speech abilities were more severely impaired than both B's and C's. His speech was much less intelligible and he made more substitution and omission errors. Traditional intervention with Subject A focused on the production of $/ \mathrm{k}, \mathrm{g} /$ in the initial position of $\mathrm{CV}$ and CVC syllable words. These sounds had been targeted previously using traditional articulation intervention through Portland Public School District and through Portland State University. For this study, a tongue depressor and candy cane were used to assist with proper tongue placement. Intervention with PTT proceeded through alveolar to alveolar transitions (e.g., ti-di) without difficulty. Treatment focused primarily on alveolar to velar (e.g., ti-gi) and velar to alveolar (e.g., ki-ti) transitions. The subject was asked to focus on the production of syllables such as $/ \mathrm{gu} /, \mathrm{go} /, / \mathrm{gi} /, / \mathrm{ko} /, / \mathrm{ku} /, \mathrm{ki} /$ in conjunction with alveolar syllables. Tactile cues of two fingers placed on the subject's throat were used to assist in eliciting the velar sounds, while one finger placed on the philtrum helped to elicit the alveolar sounds.

Subject A demonstrated improvement in percent of word intelligibility over the intervention period. The subject's intelligibility may have increased due 
to improved production of the target sounds and/or the enhanced ability to produce transitions between alveolar and velar sounds.

This subject displayed an improvement in the number of phoneme errors on the Goldman-Fristoe Test of Articulation. During pre-testing, he made numerous substitution errors. Although they were inconsistent, his sound repertoire consisted primarily of /d, p, b/ with occasional productions of /m, n, t, s, $\mathrm{t} /$. He substituted almost all consonant sounds with $/ \mathrm{b}, \mathrm{p}, \mathrm{d} / \mathrm{and}$ demonstrated substitution and omission errors for $/ \mathrm{b}, \mathrm{p}, \mathrm{d} /$ in the medial and final positions. PTT drill work appeared to benefit the subject's acquisition of $/ \mathrm{k} /$ and $/ \mathrm{g} /$. Because prior treatment focusing on the production of these sounds resulted in minimal improvement, PTT drills of $/ \mathrm{k} /$ and $/ \mathrm{g} /$ syllables appear to have helped him develop a strong sensori-motor image of the correct production of the target sounds. During post-testing, Subject A produced both $/ \mathrm{k} /$ and $/ \mathrm{g} /$ correctly in the initial position of words. He also substituted /g/ for $/ \int, t y, d r$, st/ in the initial position of words which indicates that he was more readily including this sound in his repertoire. Inconsistencies in errors were noted when comparing the pre- and posttest measures, which is typical of children with DVD (Creaghead, Newman, \& Secord, 1989; Rosenbek \& Wertz, 1972; Weiss, Gordon, \& Lillywhite, 1987).

Parent report indicated that Subject A was beginning to produce words beginning with $/ \mathrm{k} /$ and $/ \mathrm{g} /$ in his spontaneous speech toward the conclusion of the intervention period. The subject's mother attributed much of his success to the 
use of physical assistance of the tongue while instructing the subject to use the sound. The subject and family completed the home practice of PTT drills on a daily basis and gains in the subject's production of $/ \mathrm{k} /$ and $/ \mathrm{g} /$ were noted between sessions.

\section{Subject B}

Subject B received traditional intervention with emphasis on the production of $/ \mathrm{v} /$ and $/ \mathrm{t} /$ in words, phrases, and sentences. In addition, he received treatment with PTT for the final 4 weeks of intervention. He demonstrated signs of DVD such as struggles, retrials, and transpositions of sounds and syllables. He produced two-part transitions (e.g., ki-ti) easily and demonstrated more difficulty on three-part transitions (e.g., pi-ti-ki). With practice three-part transitions were accomplished. Tactile cues were used to remind the subject of lingual placement during transitions.

Subject B displayed minimal gains in percentage of word intelligibility. Gains are not likely due to an improvement in his production of $/ v /$ or $/ \mathrm{t} /$ since these sounds have not been found to contribute significantly to intelligibility (Hodson \& Paden, 1991). The increase in intelligibility may be attributed to accomplishments in the ability to produce the transitions between sounds or to listener familiarity. Because the percent increase was so minimal, it may also be due to the normal variability in intelligibility of spontaneous speech. 
This subject showed an improvement in the number of phoneme errors on the Goldman-Fristoe Test of Articulation. In comparing pre- and posttest measures he produced both $/ \mathrm{v} /$ and $/ \mathrm{t} /$ correctly in all positions of words following intervention. Some inconsistencies in the production of other consonants were noted between the two examinations which explains why his score did not reflect the improvements in $/ \mathrm{v} /$ and $/ \mathrm{t} /$. These inconsistencies are characteristic of children with DVD.

This subject made little improvement during treatment with traditional articulation therapy alone and during treatment with PTT. The subject and his family reported that they rarely completed home practice. This may explain why significant gains were not experienced.

\section{$\underline{\text { Subject C }}$}

Subject $\mathrm{C}$ received traditional articulation intervention that targeted the production of $/ f /$ and $/ / /$ in words, phrases, sentences, and spontaneous speech. In addition, he received treatment with PTT for the final 2 weeks of intervention. He demonstrated signs of apraxia such as struggles, retrials, and transpositions of sounds and syllables. He produced two-part transitions (e.g., /ki-ti) with ease and demonstrated difficulty producing three-part transitions (e.g., ki-ti-pi). Three-part transitions were accomplished with practice. Tactile cues were used to remind the subject of lingual placement during transitions. 
Subject $\mathrm{C}$ made gains in percentage of word intelligibility throughout the treatment period. Gains made during the last 2 weeks of treatment with PTT were greater than gains made during the first 4 weeks of treatment with traditional articulation intervention alone. Because the sounds targeted have not been found to contribute significantly to intelligibility (Hodson \& Paden, 1991), increases in intelligibility are not likely due to treatment with traditional articulation intervention. It is unclear why gains were made during the first 4 weeks of intervention. Improvement in intelligibility during the final 2 weeks of treatment may be attributed to enhanced ability to produce lingual transitions between syllables.

Gains were also made in the number of phoneme errors. In comparing pre- and posttest measures, improvement in the production of targeted sounds was noted. The subject produced the /f/ and / // sounds correctly in all positions of words following intervention; however, on the posttest measure, the subject substituted $/ \mathrm{J} /$ for $/ \mathrm{t} / \mathrm{and} / \mathrm{s} /$. These sounds were produced correctly during the pretest measure. This accounts for the final score not reflecting improvements in /f/ and /J/. During the summer, the subject demonstrated spontaneous improvement of $/ \mathrm{l} /$ in words.

Parent report indicated frequent home practice. Improvements between sessions were noted on the days that the family reported daily practice. 
Comparison of Gains in Percent of Word Intelligibility

Subject C, who only received treatment with PTT during the final 2 weeks of intervention, showed greater percent improvement of word intelligibility than Subjects A and B. Subject A, who received treatment with PTT during the entire intervention period, demonstrated greater percent improvement of word intelligibility than Subject B. Subject A had a greater potential for improvement; however, his speech disorder was much more severe than the other subjects and probably requires a longer duration of intervention to show comparable gains (Blakeley, 1980; Blakeley, 1983). Subject C may have made more gains than Subject A because he was developmentally ready for treatment with PTT. Subject B displayed limited gains in intelligibility which may be the result of his lack of daily practice at home. Reported participation in the home program resulted in observed benefit for Subjects A and C.

Biweekly probes reveal that Subjects A and C made significant gains in percent improvement of word intelligibility following treatment with PTT. Subject $\mathrm{C}$ also demonstrated greater improvement during treatment with PTT than during treatment with traditional articulation intervention alone. For these subjects, drills of sound sequences may have assisted in facilitating fluid lingual movements between sounds. Gains made by Subject B were minimal and may have been negatively influenced by a lack of home practice. 
Findings are inconclusive but suggest that treatment with PTT may result in a greater improvement in percentage of word intelligibility than treatment with traditional articulation intervention alone for some subjects.

\section{Comparison of Gains in the Number of Phoneme Errors}

Subject A demonstrated greater gains in the number of phoneme errors than both Subjects B and C. The fact that his potential for improvement was much greater than Subjects B and C's must be considered before making judgments about the effectiveness of PTT. Subject C, who received treatment with PTT for only 2 weeks, demonstrated greater gains than Subject B who received intervention with PTT for 4 weeks. Subject B's limited improvements may be due to lack of home practice.

\section{Conclusion}

Findings of this study are inconclusive and fail to provide support for the effectiveness of PTT. The literature suggests that intervention with children who have DVD requires a longer duration than with children who have functional articulation or phonological processing disorders (Blakeley, 1980; Blakeley, 1983). It may be that investigation over a longer duration of intervention would reveal evidence about the effectiveness of PTT.

Considering parent report and comparison of pre- and posttest measures, it appears that PTT in addition to a traditional articulation approach facilitates 
improvements in intelligibility and the number of phoneme errors. Findings suggest that treatment with PTT results in greater gains in intelligibility than treatment with traditional articulation intervention alone for some subjects. It may be that PTT assists children differently according to their individual needs. For children such as Subject A, whose sound repertoire was extremely limited, PTT may facilitate the acquisition of target sounds by helping the child to form strong sensori-motor images of phoneme production and two-part transitions containing the target sound. For children such as Subject C, PTT may encourage coordination for lingual movements of multiple-part transitions. In either case, PTT may assist in facilitating the sequencing of movements for the production of speech.

A home program is a viable portion of any program that attempts to generalize skills learned in the clinic to the child's natural environment. Results of this study indicated that a home program is also a useful component in this approach to remediation. Daily practice of the drills may have significantly contributed to gains made by two of the subjects. Subject B made minimal gains during treatment with traditional articulation intervention alone as well as treatment with PTT. A lack of the daily practice seemingly hindered his improvement. For the other two subjects, home practice may have offered the repetition necessary to establish sensori-motor images of multiple-part transitions. 


\section{CHAPTER V \\ SUMMARY AND IMPLICATIONS}

\section{Summary}

Three children who presented with characteristics of developmental verbal dyspraxia (DVD) received Planned Transitions Therapy (PTT) in conjunction with traditional articulation intervention. Initially, continuous speech samples of each subject were obtained and analyzed to measure percentage of word intelligibility. The Goldman-Fristoe Test of Articulation was administered to determine the number of phoneme errors. Each subject participated in treatment with traditional articulation intervention. In addition, Subject A received PTT during the entire 6-week intervention period. Subject B received PTT for the final 4 weeks of intervention and Subject C received PTT for the final 2 weeks. Biweekly measures of percentage of word intelligibility were also taken.

At the conclusion of the 6-week intervention period, percentage of word intelligibility was reevaluated. The number of phoneme errors was determined for each subject through re-administration of the Goldman-Fristoe Test of Articulation. The pre-and post-test results were compared. All subjects demonstrated improvements in both percentage of word intelligibility and the number of phoneme errors. Subject $\mathrm{C}$ displayed greater percent improvement of word intelligibility than Subjects A and B, and Subject A demonstrated greater 
percent improvement than Subject B. Improvements in the number of phoneme errors were greater for Subject A than Subjects B and C; however, Subject C made greater gains than Subject B.

\section{Implications}

\section{$\underline{\text { Clinical }}$}

Findings of this study are inconclusive and leave many questions about the treatment of DVD. They warrant the need for analysis in a different manner or further research using this approach to its remediation. As discussed in the literature review, there is a strong need for an effective intervention approach to use when working with children who present with DVD. The literature indicates that deficits in the ability to sequence movements of the articulators in the formulation of speech are a predominant characteristic of this disorder. Improvement of this ability is addressed in remediation with PTT.

Findings suggest, but do not prove, that PTT facilitates improvement in intelligibility and the number of sound errors. This approach to intervention may assist children such as Subject A whose sound repertoire was limited by helping to establish strong mental-physical images of phoneme production. For children with DVD whose speech is more mature, PTT may facilitate coordination of lingual movements for the production of speech. 
Daily home practice appeared to benefit two of the subjects in this study. A lack of home practice by one of the subjects appeared to limit his gains. Daily practice is seemingly a useful component to this approach, as it is in the acquisition of most skills.

\section{$\underline{\text { Research }}$}

Additional research questions may be considered. This study combined PTT with a traditional program of articulation intervention. Phonological processing approaches to the remediation of articulation disorders have recently been strongly advocated (Hodson \& Paden, 1991). Further research might explore the effectiveness of PTT in conjunction with phonological processing intervention in the treatment of children with DVD.

Results of this investigation are fairly inconclusive. This may be due to the small sample size. Investigation on a larger scale might be completed to evaluate the effectiveness of PTT. Comparison of multiple single-subject studies or one study including many subjects may be used to evaluate its effectiveness. In addition, further investigation of PTT as a viable intervention approach for DVD might measure gains over a longer period of intervention. The literature suggests that children with DVD require intensive therapy over a longer period of time than children with functional articulation disorders (Blakeley, 1980; Blakeley, 1983). During this study change was measured over a 6-week intervention period. 
Subject A demonstrated some gains following the 6 weeks of intervention with PTT. A longer period of intervention may have resulted in even greater gains. 


\section{REFERENCES}

Aram, D. (1984). Preface. Seminars in Speech and Language, 5, ii-v.

Bashir, A., Grahamjones, F., \& Bostwick, R. (1984). A touch-cue method of therapy for developmental verbal apraxia. Seminars in Speech and Language, 5 , 127-137.

Bernthal, J., \& Bankson, N (1993). Articulation and phonological disorders. Englewood Cliffs, NJ: Prentice Hall.

Blakeley, R. (1980). Screening test for developmental apraxia of speech. Tigard, OR: CC Publications, Inc.

Blakeley, R. (1983). Treatment of developmental apraxia of speech. In W. Perkins (Ed.), Current therapy of communication disorders: Dysarthria and apraxia (pp. 25-33). New York: Thieme-Stratton, Inc.

Cermak, S. (1985). Developmental dyspraxia. In E. A. Roy (Ed.), Neuropsychological studies of apraxia and related disorders. (pp. 225-248). North Holland: Elsevier Science Publishers Co.

Chappell, G. (1973). Childhood verbal apraxia and its treatment. Journal of Speech and Hearing Disorders, 38, 362-369.

Chumpelik, D. (1984). The prompt system of therapy: Theoretical framework and applications for developmental apraxia of speech. Seminars in Speech and Language, 5, 139-156. 
Crary, M. (1984). Phonological characteristics of developmental verbal apraxia. Seminars in Speech and Language, 5, 71-83.

Creaghead, N., Newman, P., \& Secord, W. (1989). Assessment and remediation of articulatory and phonological disorders (2nd ed.). Colmbus, $\mathrm{OH}$ : Merrill Publishing Co.

Darley, F., Aronson, A., \& Brown, J. (1975). Motor speech disorders. Philadelphia: W. B. Saunders Co.

De Renzi, E., Piezuro, A., \& Vignolo, L. (1966). Oral apraxia and aphasia. Cortex, 2, 50-73.

Dunn, L., \& Dunn, L. (1981). Peabody picture vocabulary test - revised. Circle Pines, MN: American Guidance Service.

Goldman, R., \& Fristoe, M. (1986). Goldman-Fristoe test of articulation. Circle Pines, MN: American Guidance Service.

Groenen, P., Maassen, B., Crul, T., \& Thoonen, G. (1996). The specific relation between perception and production errors for place of articulation in developmental apraxia of speech. Journal of Speech and Hearing Research, 39 . $468-482$.

Hall, P. (1992). At the center of controversy: Developmental apraxia. American Journal of Speech-Language Pathology, 1, 23-25. 
Haynes, S. (1985). Developmental apraxia of speech: Symptoms and treatment. In D. F. Johns (Ed.), Clinical management of neurogenic communication disorders. (2nd ed., pp. 259-266). Boston: Little, Brown \& Co.

Helfrich-Miller, K. (1994). A clinical perspective melodic intonation therapy for developmental apraxia. Clinics in Communication Disorders, $4,175-$ 182.

Hodson, B., \& Paden, E. (1991). Targeting intelligible speech: A phonological approach to remediation. Austin, TX: Pro-Ed.

Klick, S. (1994). Adapted cuing technique: Facilitating sequential phoneme production. Clinics in Communication Disorders, 4, 183-189.

Marion, M., Sussman, H., \& Marquardt, T. (1993). The perception and production of rhyme in normal and developmentally apraxic children. Journal of Communication Disorders, 26, 129-160.

Rosenbek, J., Hansen, R., Baughman, C., \& Lemme, J. (1974). Treatment of developmental apraxia of speech: A case study. Language, Speech, and Hearing Services in Schools, 5, 13-22.

Rosenbek, J., \& Wertz, R. (1972). A review of 50 cases of developmental apraxia of speech. Language. Speech, and Hearing Services in Schools, 3, 23-33. Rosenthal, J. (1994). Rate control therapy for developmental apraxia of speech. Clinics in Communication Disorders, 4, 190-199. 
Rylant, C., \& Gammell, S. (1985). The relatives came. New York, NY: Aladdin Papperbacks.

Square, P. (1994). Treatment approaches for developmental apraxia of speech. Clinics in Communication Disorders, 4, 151-161.

Stackhouse, J. (1992). Developmental verbal dyspraxia I: A review and critique. European Journal of Disorders of Communication, 27, 19-34.

Stackhouse, J., \& Snowling, M. (1992). Developmental verbal dyspraxia II: A developmental perspective on two case studies. European Journal of Disorders of Communication, 27, 35-54.

Weiss, C., Gordon, M., \& Lillywhite, H. (1987). Clinical management of articulatory and phonologic disorders. Baltimore, MD: Williams \& Wilkins.

Winitz, N. (1984). Treating articulation disorders. Baltimore, Maryland: University Park Press.

Yoss, K., \& Darley, F. (1974). Developmental apraxia of speech in children with defective articulation. Journal of Speech and Hearing Research, 17, $339-416$.

Young, E., \& Hawk, S. (1955). Moto-kinesthetic speech training. Palo Alto, CA: Stanford Univ. Press. 
APPENDIX A

INFORMED CONSENT 


\section{INFORMED CONSENT}

I, , the parent of hereby

agree to allow my child to serve as a subject for the investigation of: The Effectiveness of Planned Transitions Therapy in the Treatment of Three Children with Developmental Verbal Dyspraxia. This study is conducted under the supervision of Emily M. Campbell.

I understand that this study involves my child's participation in an intervention technique designed to improve his speech intelligibility and the number of phonemes in error.

I understand that there is no risk involved in this study. The only inconvenience involves my time of 60 minutes of intervention per week, and 5 minutes of daily home practice with my child. My child must not receive additional articulation or phonological intervention during participation in this study.

It has been explained to me that the purpose of this study is to learn if Planned Transitions Therapy will improve the speech intelligibility and number of sounds in error of children who present with developmental verbal dyspraxia.

I may receive direct benefit through participation in this study. Direct intervention and the enhanced environment for speaking may result in improved communication skills for my child. My participation in this study may also help to increase knowledge which may benefit others in the future.

Emily M. Campbell has offered to answer any questions that I may have about the study and what is expected of me and my child. I have been assured that all information I give will be kept confidential and that the identity of my child will remain confidential.

I have read and understand the foregoing information and agree to my child's participation in this study.

Signature Date

If you experience problems as a result of your participate in this study, please contact the Chair of the Human Subjects Research Review Committee, Office of Graduate Studies and Research, 105 Neuberger Hall, Portland State University, (503) 725-3423. 
APPENDIX B

TRADITIONAL ARTICULATION INTERVENTION PROCEDURES 
TRADITIONAL ARTICULATION INTERVENTION PROCEDURES

\section{Instructions}

Phonemes to be targeted are to be determined through administration of the Goldman-Fristoe Test of Articulation. Priority is given to sounds according to the typical developmental sequence of acquisition and to the degree of stimulability.

The traditional articulation approach to be used will begin with emphasis on sounds in isolation, and progress through sounds in the initial, medial, and final positions of syllables and words, sounds in phrases, sounds in sentences, sounds in conversation, and then carryover of sounds to environments outside of the clinic room. A criterion of $8 / 10$ should determine movements from one step to the next.

To establish correct production of the sounds, the investigator should use moto-kinesthetic, visual, and verbal models and cues. If necessary, the investigator may physically assist the tongue, and touch lips and neck to cue proper placement of the articulators.

Picture cards representing words that contain the target sound(s) are to be used during a variety of motivating and interesting activities, such as fishing and flashlight games. Responses should be reinforced as the investigator judges necessary for each subject. Tangible reinforcement should be given as a means of 
extrinsic motivation. Reinforcement material may be chosen based on each subject's interests.

A home program is to be implemented in which the subjects are required to complete 5 minutes of daily practice at home with their parents/caregivers. Picture cards of words that contain the subjects' target sound(s) for the previous session should be given to the subject to take home. The parents/caregivers are to be instructed to play games such as Concentration or Bingo with their children as a means of stabilizing the correct phoneme productions and generalizing them to other environments. The parents/caregivers are to be instructed through observation of the clinical session and through direct instruction on how to reinforce their child's productions. 
APPENDIX C

PLANNED TRANSITIONS THERAPY PROCEDURES 


\section{PLANNED TRANSITIONS THERAPY PROCEDURES}

\section{Instructions}

For these exercises the subjects' mouth should remain approximately halfway open, so that the tongue is completing most of the movement without assistance from the jaw. To stabilize the lower jaw, 1/2 of a tongue depressor split lengthwise can be placed between the subjects' molars. If necessary, the tongue tip should be assisted to elevate through use of a tongue depressor to ensure as accurate a production as possible.

The following steps represent a logical progression for intervention; however, they may be changed or interchanged with the needs of the subject. There is no criterion required to move from one group to the next. Intervention should begin with sequences targeted from steps one through eight. Subjects are to practice at least two types of movement patterns from the first 8 groups of transitions during each session, and to slowly increase the number of targeted transitions as proficiency increases. Sequences from steps nine and ten should be targeted when the subjects are capable of performing movement patterns from the first 8 groups.

Subjects will be required to complete 5 minutes of daily home practice with the assistance of their parents/caregivers. Home practice will consist of drills emphasizing the movement transitions targeted during the previous session. 
Parents/caregivers will be instructed through observation of the clinical session and through direct instruction on how to perform home practice with their children.

During steps one and two, verbal instructions should be given to the subject to produce "tongue tip taps". Physical stimulation of the alveolar ridge can be performed to facilitate correct placement of the tongue tip. In addition, kinesthetic cues in which the clinician touches the subject's philtrum can be used as reminders of proper tongue placement. In Group 2 , if $/ /$ is not yet part of the subject's repertoire, then $/ \mathrm{n} /$ syllables can be produced in sequence with $/ \mathrm{d} /$ or $/ \mathrm{t}$ syllables. The following syllables are written using phonetic symbols.

One

$\begin{array}{llllll}\text { te } & \rightarrow & \text { de } & \text { ne } & \rightarrow & \text { le } \\ \text { ti } & \rightarrow & \text { di } & \text { ni } & \rightarrow & \text { li } \\ \text { tal } & \rightarrow & \text { daI } & \text { nal } & \rightarrow & \text { las } \\ \text { to } & \rightarrow & \text { do } & \text { no } & \rightarrow & \text { lo } \\ \text { tu } & \rightarrow & \text { du } & \text { nu } & \rightarrow & \text { lu }\end{array}$

During steps three through eight, physical assistance can be given to assist movement from the tongue tip position for alveolar sounds to the posterior position for velar sounds and vice a versa. In addition, motor-kinesthetic cues in which the clinician touches the philtrum and throat should be used. 
Three

$\begin{array}{lll}\text { te } & \rightarrow & \mathrm{ke} \\ \text { di } & \rightarrow & \mathrm{ki} \\ \text { nal } & \rightarrow & \mathrm{kaI} \\ \text { lo } & \rightarrow & \mathrm{ko}\end{array}$

\section{Five}

ke

ki

kal

ko

$\mathrm{ku}$

$\rightarrow$

$\underline{\text { Seven }}$

te<smiles>[1H][1H]</smiles>

di

naI

lo te

ti

tal

to

tu

eๆ

in

arn

on
Four

$\begin{array}{lll}\text { gu } & \rightarrow & \text { tu } \\ \text { go } & \rightarrow & \text { do } \\ \text { gi } & \rightarrow & \text { ni } \\ \text { ge } & \rightarrow & \text { le }\end{array}$

$\underline{\text { Six }}$

$\begin{array}{lll}\text { de } & \rightarrow & \text { ge } \\ \text { di } & \rightarrow & \text { gi } \\ \text { dal } & \rightarrow & \text { gai } \\ \text { do } & \rightarrow & \text { go } \\ \text { du } & \rightarrow & \text { gu }\end{array}$

Eight

en $\rightarrow \quad$ le

$\operatorname{arm} \quad \rightarrow \quad$ ni

un $\quad \rightarrow \quad$ daI

on $\rightarrow$ to 
To incorporate bilabial sounds within the production of smooth transitions, steps nine and ten should be used. Motor-kinesthetic cues in which the clinician touches the lips for bilabial sounds, the philtrum for alveolar sounds, and the throat for velar sounds can also be utilized.

\section{$\underline{\text { Nine }}$}

\begin{tabular}{|c|c|c|c|c|c|c|c|c|}
\hline pe & $\rightarrow$ & te & $\rightarrow$ & ke & be & $\rightarrow$ & te & $\rightarrow$ \\
\hline pi & $\rightarrow$ & $\mathrm{ti}$ & $\rightarrow$ & ki & bi & $\rightarrow$ & $\mathrm{ti}$ & $\rightarrow$ \\
\hline pal & $\rightarrow$ & tal & $\rightarrow$ & kaI & bar & $\rightarrow$ & taI & $\rightarrow$ \\
\hline po & $\rightarrow$ & to & $\rightarrow$ & ko & bo & $\rightarrow$ & to & $\rightarrow$ \\
\hline pu & $\rightarrow$ & tu & $\rightarrow$ & ku & bu & $\rightarrow$ & tu & $\rightarrow$ \\
\hline
\end{tabular}

$\underline{\text { Ten }}$ 
APPENDIX D

PRE- AND POSTTEST MEASURES 
PRE- AND POSTTEST MEASURES

\begin{tabular}{lccc}
\hline & Subject A & Subject B & Subject C \\
\hline Pretest 1 & 37 & 76 & 73 \\
Pretest 2 & 40 & 70 & 78 \\
Pretest 3 & 39 & 72 & 70 \\
Average & 39 & 73 & 74 \\
\hline & & & \\
\hline & Subject A & Subject B & Subject C \\
\hline Posttest 1 & 48 & 79 & 79 \\
Posttest 2 & 46 & 73 & 85 \\
Posttest 3 & 52 & 77 & 81 \\
Average & 49 & $76_{z}$ & 82 \\
\hline
\end{tabular}

